\title{
IMPROVING NON-REPETITIVE TAKT PRODUCTION WITH VISUAL MANAGEMENT
}

\author{
Max Grönvall' ${ }^{1}$ Henri Ahoste ${ }^{2}$, Joonas Lehtovaara ${ }^{3}$, Ana Reinbold ${ }^{4}$, and Olli \\ Seppänen ${ }^{5}$
}

\begin{abstract}
Takt production is gaining increasing visibility in the construction industry. To further improve the current takt production practices, visual management tools could offer improved efficiency in the production control phase. However, the effects of visual management in takt control setting have not yet received much attention in research.

This study aimed to investigate the effects of various visual tools in a takt production setting to gain knowledge on how these tools could aid takt control efficiency. The research utilized a design science research approach to create visual management tools and iterate them based on feedback. Interviews, site observation, and takt progress tracking were used to evaluate the implemented tools.

The findings indicate that workers on site want to be more aware of the production plan, and information helps them to work in the right location at the right time. To help workers, visual management tools need to recognizable, explicit, and contain correct and up-to-date information. However, there are cultural issues related to implementation, especially on the need for information going through foremen to crews.
\end{abstract}

\section{KEYWORDS}

Visual management, takt control, lean construction, takt production, production planning and control.

\section{INTRODUCTION}

Compared to other industries, construction productivity development has remained low (Forbes \& Ahmed, 2011). Takt production is the most recent production planning and control method introduced to answer the productivity problem (Heinonen \& Seppänen, 2016; Chauhan et al., 2018). Indeed, studies of takt production have shown potential in increasing production flow, also contributing positively to productivity (Lehtovaara et al., 2021).

1 Development Engineer, Skanska Oy, Finland, max.gronvall@ skanska.fi, orcid.org/0000-0001-8635$\underline{128 \mathrm{X}}$

2 Production Engineer, Skanska Oy, Finland, henri.ahoste@skanska.fi, orcid.org/0000-0002-5932-3758

3 Doctoral Candidate, Department of Civil Engineering, Aalto University, Finland, Joonas.lehtovaara@aalto.fi, orcid.org/0000-0002-4761-3811

4 Doctoral Candidate, Department of Civil Engineering, Aalto University, Finland, ana.reinbold@aalto.fi, orcid.org/0000-0002-7774-7984

5 Associate Professor, Department of Civil Engineering, Aalto University, Finland, olli.seppanen@aalto.fi, orcid.org/0000-0002-2008-5924 
The term "takt" originates from manufacturing, denoting a constant time in which individual production activities should be finished (Hopp and Spearman, 2011). In construction, takt production consists of planning and control functions. Takt planning aims to identify repetitive processes in production and to balance them to decrease variability, forming a central element to establish flow-efficient production (Dlouhy et al., 2016). It is also essential to sustain flow-efficient through production by continuously controlling and improving the system (Lehtovaara et al., 2021).

Several benefits related to takt production have been reported in the literature. Yassine et al. (2014) argued that lead time will shorten, construction costs will diminish, and waste is reduced, while productivity is increased (Vatne \& Drevland, 2016). In addition, takt production has been documented to increase transparency, ease communication between subcontractors, and enable more even production while making production forecasting and control more accurate (Frandson \& Tommelein, 2014; Dlouhy et al., 2018). Studies of takt production have emphasized takt planning function, while takt control has had a lesser role. Lehtovaara et al. (2021) presented a theoretical model which proposes that takt control enables reducing rework, making-do, and re-entrant flow. Increased stability and reliability, problem-solving, and transparency are effects of both effective takt control and continuous improvement. Although Schöttle and Nesensohn (2019) presented challenges with lack of commitment in takt control. Reasons for the lack of commitment were lack of coordination, lack of understanding the production system and missing information from own company.

One possible way to potentially leverage the positive effects of takt control and continuous improvement is the adoption of visual management (VM) tools. VM is defined by Greif (1991) as the use of information in a visual manner to those who are executing the task in a way that the information can be retrieved at a glance and immediately be transferred to the task execution. VM tools could improve the transparency regarding the task to be executed, resulting in a better and more continuous production flow. VM aims to transform the workplace and task execution into selfexplanatory, self-ordered, and self-regulated action while facilitating continuous improvement (Galsworth, 1997). This results in transparency, discipline, management by facts, simplification, and unification, and creating shared ownership (Tezel et al., 2009).

The adoption of VM could increase production transparency and enable more effective identification of waste and disruptions in the production flow (Formoso et al., 2002), which are also associated with Lean Production (Liker, 1997). VM as a part of lean thinking has been a vital management approach to increase information distribution, bringing more transparency to the construction site, and enabling pull production approaches with more simple and targeted communication tools (Koskela et al., 2018).

VM tools can be relatively simple, like a board that has information and visual aids such as production plans (Tezel et al., 2015). Valente et al. (2018) introduced standardized worksheet cards that include information about what work needs to be done and where and the time it takes to complete and sequence steps. Another tool in their study was a constraint analysis board that includes a picture of layout, schedule of activities, and constraints, which supports collaboration between stakeholders. Valente et al. (2018) also pointed out in their proposed model that the final step is to make visual tools visible, which needs to be taken into account in the design of visual tools. These design decisions could include issues such as color, shape, texture, and symbols. (Valente et al., 2018)

It could be argued that takt production and VM objectives are closely aligned. Takt production is used to plan and control the pace with which the processes should happen 
(Lehtovaara et al., 2021). VM can be used to communicate the requirements to workers and explain who is to execute what and when, providing a transparent view of production flow and how an individual's work can contribute to completing the project objectives. Contribution can produce a positive side effect of increasing the ownership of the tasks and the workers' commitment to continuous improvement with more self-managed and proactive crews (Reinbold et al., 2020).

Inspired by this evident but little investigated synergy of takt production and VM, this study aims to implement VM tools and monitor whether they improve takt control process, and further examine how VM can be harnessed to support takt control most efficiently. Three VM tools were implemented and individually analyzed. The goal is also to improve these VM tools as part of the takt control process.

The remainder of the paper is structured as follows. Next presented is the introduction of research method and the case study, in which the VM tools are implemented. The iteration process of creating the tools and the central results are introduced in the findings. Then, the overview of VM on the project and analysis of the tools' effectiveness is discussed. Finally, conclusions are presented by assessing study implications and avenues for future research.

\section{RESEARCH METHODS}

The research strategy of this paper is design science research, which aims to create a foundation for pragmatic research and solve practical challenges (Dresch et al., 2015); effectiveness of VM and takt control is a practical challenge on site and needs a pragmatic research approach. According to Holmström et al. (2009), in design science research, the aim is to create an artefact used to resolve a problem and meet a specific goal.

The design science research was carried out by utilizing a case study. According to Yin (2009) the need for a case study is when a phenomenon is studied in an actual context. In this study, the context is an ongoing construction site. The study structure mimicked the process described by Holmström et al. (2009). The first phase was problem defining. The problem in this study was site workers lack of commitment to takt production and understanding of the takt plan. The second phase was the refinement of the solution. The artefacts in this research are the specific VM tools which are used to display takt on site. The artefacts were created together with site personnel and were compared with literature about VM. The main requirement for these tools was to make them simple. The artefacts will be presented in the findings section, where the iteration process and VM tools updates will be shown. In the final phase, theoretical suggestions on how to use the information in practice were created, which is presented in the discussion section.

The case project for this study is a new 135500 sqm 2 shopping center. Construction time is from the beginning of 2019 to the spring of 2022. The shopping center has three stories with over 80 different shops, restaurants, and services. Production planning for the interior phase has been done by takt planning collaboratively with subcontractors. The interior phase has been divided into two parts, with the first part consisting mainly of MEP-frame works, interior walls, and painting of the inner roof, with a takt time of 5 days. The second part consists of work activities mainly of finishing work and ending to MEP functioning testing with a takt time of 2 days. The takt area size has been reduced for the second part of the takt plan to consist of a retail space-specific takt area.

Data collection was mainly conducted by structured interviews on-site, site observation, and tracking of takt wagons in the test area. The test area was set for takt areas 1 to 6 on the ground floor's west and east side, respectively. Figure 1 shows the test 
area with a green line and how it was divided into takt areas. The areas chosen needed to have a similar layout, area size, and takt work activities. VM tools were implemented in the west area. East area was used as a comparison area with the traditional process to compare data. The interviews were conducted on site and in total of 36 subcontractors' workers were interviewed, in which 21 worked in the west area and 15 in the east area. The interviews consisted of two parts: the first part of the interviews included questions about how well takt related requirements were met on a scale of 1 (bad) to 5 (excellent), and the second part included questions about VM. The questions and results are presented in the findings section.

Takt progress tracking was done by analyzing completion rates for each takt wagon. Takt wagons analyzed were from the test areas and the tracking was conducted for eight weeks.

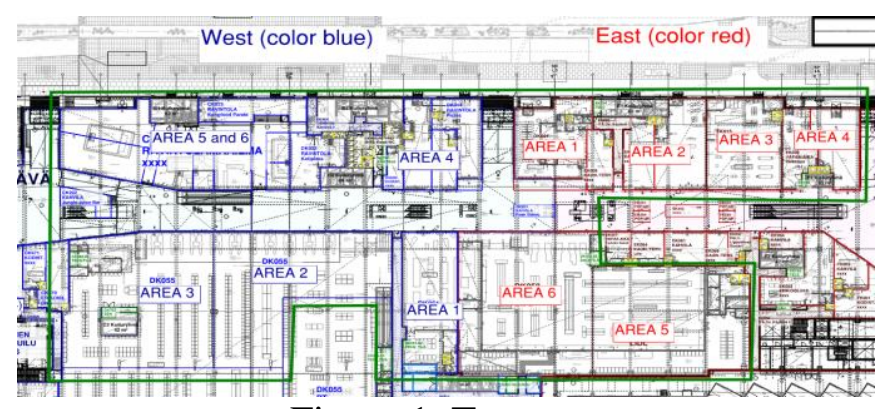

Figure 1. Test area

\section{FINDINGS}

Three VM tools were tested on the site. The main focus was on VM tools that aid the individual workers. The implemented VM tools were (1) takt plan visible to site, (2) takt wagon visualization through takt cards, and (3) takt area markings on site. In addition, crew colorings were used to complement these three tools. These VM tools on site are shown in Figure 2. Next, the tools and the iteration process are introduced.

\section{TakT Plan Visible to Site}

Takt plans that were put on site on a takt board included the whole project's takt schedule and takt areas, shown in Figure 2. These takt boards were placed on three floors and two per floor, one for the west block and one for the east block. After some discussion on site with the subcontractors, the information of supervisors per section and foremen controlling different takts were updated as the first iteration on the takt boards. Takt boards were the first VM tools set up on site, and their implementation was done earlier than the other tools. In addition, one takt board in the main lobby at the site was updated as a second iteration to contain information on a three-week schedule for each subcontractor. The three-week schedules were updated weekly.

Takt plans visible on site got positive feedback early on from the subcontractors, and they felt that the information was important. Interviewees felt that the takt boards were easily accessible and found on site. Most of the interviewees also felt the takt plan was easily understandable, but some felt that it was hard to understand. Adding subcontractors' three-week lookahead plans on the takt boards was seen crucial for maintaining work flow as part of takt control. It also helped to make the takt plan more understandable for those who thought the whole takt plan was hard to understand. Takt boards were also used as a tool for coordination with the general contractor's foremen and subcontractors' team 
leaders as well as coordination between subcontractors. The interviewees pointed out that the significance of production plan in production control is lesser when the worker is further in the subcontracting chain.

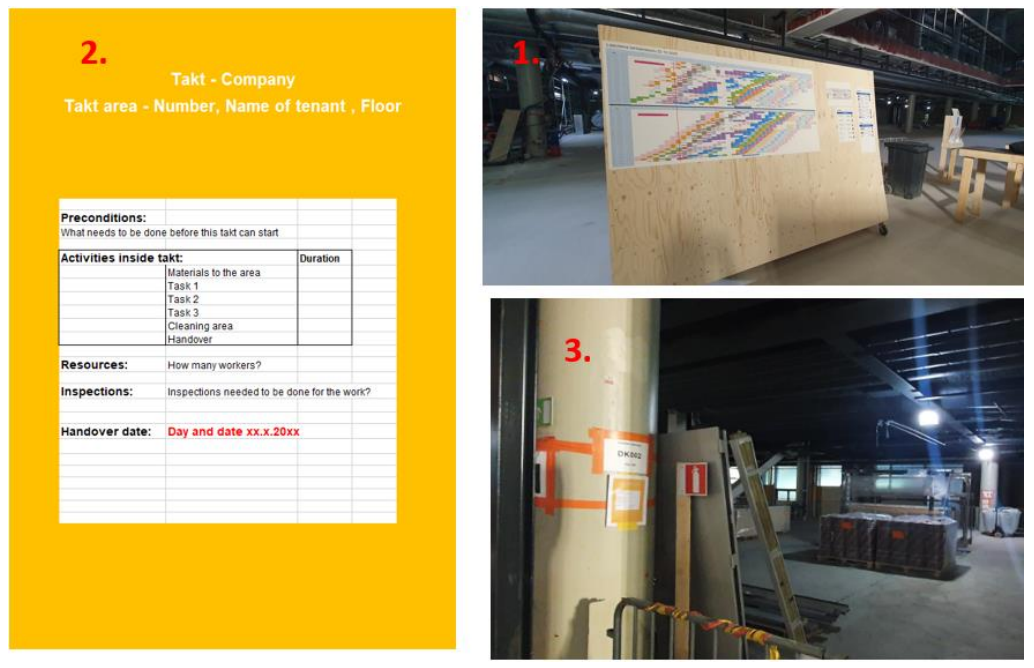

Figure 2. Visual management tools shown on site.

\section{TAKT Wagon Visualization Through TakT CARDS}

The initial idea of takt cards was developed from Kanban cards, takt wagon visualization from an observation of two construction projects in San Francisco ${ }^{6}$, and the need to show more detailed information to the working crews. Most of the information displayed on the takt cards are issues that were discussed in the takt planning meetings but never really visualized on site. The main focus of takt cards was to make them visually recognizable. Before the first iteration, takt cards contained a lot of information but were later simplified. An example of a takt card is shown in Figure 2.

The first iteration of takt cards, which were implemented on site, included information about preconditions, tasks inside the takt, resources needed for the wagon, inspections done within the wagon, and handover date. Through feedback, the second iteration was to add a three-week lookahead plan, which contained the information about the next two takt wagons in the takt area. The three-week lookahead plans were placed beside the takt cards, which were located near the entrance to the takt areas, to be easily visible to people who seek information. The entrace to takt areas was seen as the optimal location for takt cards by interviewees. The third iteration considered making the takt cards more visible. An information board was made and previously mentioned items were added on it as well as a lamp and takt area room identification numbers. This iteration made the takt card as a whole more recognizable as it was bigger in size and had a lamp to gain more attention.

Some of the takt wagons are straightforward work that do not need a lot of information, and the takt boards are enough, as few interviewees pointed out. However, takt cards were seen useful if the cards were bigger and only contained essential information for crews. If there is too much non-essential information the tool was seen as unnecessary. The takt cards were seen to need more instructions. The information should be clear, not too complicated, and recognizable. Essential information for takt control was schedule information about prerequisites of tasks in takt, currents task details, and the next takt wagon. The research area had different sized takt areas and the interviewees thought that

6 Grönvall, M. 2019. Tahtituotannon implementointi toimitilarakentamisessa. (Master's Thesis). 
the takt cards work better in smaller areas in the finishing phase, with multiple tasks in one takt. The study also pointed out that VM system in non-repeatable takt production requires a lot of work to have the real-time information when done manually. Using takt cards for every takt area in the project would scale the problem.

\section{TAKT Area Markings On Site}

The initial idea for takt area markings was to spray the outlines of the area on the floor and use columns to show the area with a paper tag. Due to COVID-19 restrictions, the research was delayed, and most of the areas already had natural boundaries by interior walls. After discussions with the project members on how to show the takt areas on site, the thought was to implement the room numbers by projecting the numbers with light, but it wasn't possible due to time limits of this study. Finally, the takt areas were tagged with the room identification numbers and space purpose or name on columns in the area, as shown in Figure 2.

Through iteration of takt cards, the room identifications were attached to the same board as the takt cards. Most parts of the test areas were smaller spaces with only one entrance to the area. With larger areas that had to be split into different takt areas, f.e. west areas 2 and 3, the takt area markings should be shown more visually. Takt area markings should be visible from every side of the area, and the marking should not be only in one place. One interviewee also thought that the takt area outlines should be more visible, but it also depends on what work is done in the area. Area markings with room or area identification helped workers to mark where they had been working. The site layout was mostly seen as easily understandable. Overall, takt area markings with the help of takt boards with project layout and takt areas were seen as essential for takt control. Most workers gave good grades for the visualization and clarity of takt area markings as the average was 4,19 out of 5. Subcontractors working in the larger areas gave worse feedback as mentioned above.

\section{Crew Coloring Related to Takt Wagons}

Crew coloring was done to match takt cards and takt wagons in the schedule with the color of the company's clothing or logo to make it visually easier to recognize where a crew is needed to be and to control the work. One example is the interior wall subcontractor with red clothes, so their takt and takt card is red. Interviews indicated that most thought that the takt schedule was clear and that some subcontractors did not see their takt cards in the right place. It shows that colors used for takts made it also beneficial to keep track of where their own work was going. Using of colors may have many meanings which was pointed out by a interviewee. The interviewee thought that a green takt card meant that the area was finished by this subcontractor. Although it was a color for the electricity subcontractor and it resulted in the misunderstanding of takt cards.

\section{IMPLEMENTATION RESULTS}

Takt progress tracking showed that the west area which implemented VM tools had better average progress. The area had $11 \%$ higher results on completed takt wagons than the control area. The challenge with analyzing progress tracking and the effect on takt is the external impact of Covid-19 on subcontractors' resources. This also affected completion progress as the results started decreasing, as the production was running behind from week 5 of testing onward.

Table 1 presents that takt production features were on a good level in the opinion of interviewees, even though production was running late. There was not a straightforward 
correlation between VM tools and takt plan progress, but as production started running late of the takt schedule, the need for VM tools also started decreasing. This was due to the fact that because the progress tracking was not accurate anymore, the workers partially lost their interest towards the tools. One finding in conflict is that the workers only thought that VM tools help a bit, even though most of them thought there should be more VM information on site. The results were impacted by takt cards not being in real-time and by delays with progress.

Table 1. Interview questions and results

\begin{tabular}{|c|c|}
\hline Questions & Results \\
\hline $\begin{array}{l}\text { How well the following are met: work preconditions, } \\
\text { clarity of schedule, takt areas and work content, working }\end{array}$ & 4.3 (west) \& 4.1 (east) \\
\hline without interference. & 5 had seen $(14 \%)$ \\
\hline Have you seen or used VM tools earlier? & "Helps a bit" \\
\hline Do VM tools support your work? & Close to work place on site (91\%) \\
\hline $\begin{array}{l}\text { Should the VM tools be located close to workplace or } \\
\text { inside site office? }\end{array}$ & $53 \%$ would want more information \\
\hline Would you like more VM information on site? & $\begin{array}{c}50 \% \text { could help to create VM } \\
\text { tools }\end{array}$ \\
\hline $\begin{array}{l}\text { Could you help to create VM tools that support your } \\
\text { work? }\end{array}$ & \\
\hline
\end{tabular}

As summary, the three VM tools provided benefits for production control, but they also need to be developed further to reach full potential. Takt boards were seen to have the most positive effect on production. They made the production plans understandable to most of the workers. Takt boards were also a place for daily coordination of production control. However, takt cards did not achieve their full potential in this study and need further development. The main focus on takt cards is to make them visual and located in a central place to gain attention from workers. Takt cards were seen as a useful tool if they have the right information, which can differ for different takts, takt areas, or crews. Takt area markings with the aid of takt boards were seen essential for takt control. Simple signs like room identifications on columns were seen as an adequate solution. It is important to use takt area markings that suit best for the takt area and are visible from different sides if it is an open space. Color coding in visualizing takt plan on site needs to be made clear, since different colors can create misunderstanding.

\section{DISCUSSION}

Tezel et al. (2015) presented that VM tools should be simple and have visual aids like plans. This matter was seen important with takt boards on site. Valente et al. (2018) also presented the benefit of using boards as supporting collaboration between stakeholders. The study showed that using takt boards enables coordination on site, likely decreasing rework and re-entrant flow and increasing transparency and identification of disruptions. These benefits of VM in production flow were also pointed out by Liker (1997) and Formoso et al. (2002). These introduced benefits also have a positive effect on takt control. The problem with some parts of the interviews compared to observation and conversations is that the interviewees did not completely understand takt boards as VM tools.

Takt cards were not used to their full potential and were not recognizable enough in size, which brought the problem of giving enough information to the subcontractor. 
Valente et al. (2018) presented that the final step is to make tools visible, which is an important aspect also highlighted in this study. Takt cards were manually changed, which brings the problem of having the updated card on site. Updating takt cards should be digitalized in the future, as Reinbold et al. (2020) pointed out. The challenge of takt cards not being real-time is also present if the work isn't completed as in the production plan. The challenge of not having real-time information is also introduced by Reinbold et al. (2020). It brings up trust issues, as interviews also pointed out. Results indicate that if takt cards' information is not in real-time, it decreases trust in overall VM tools for takt control. One aspect that challenged the thought of takt cards decreasing the need to contact foremen was, that the information needed isn't shown in takt cards. To solve these problems it is essential to ensure the right level of information that benefits the workers.

Takt production itself gave sound basis for the implementation of VM tools. The general feedback from subcontractors was that takt schedules were visually clearer and easier to understand than traditional schedules. Most of the tools' information was already present and only needed to be made visually recognizable on site. In the beginning, it was challenging to get the workers on site to understand VM tools and the connection to their work, which made it challenging to see the results of these tools. At a takt planning meeting, the tools were introduced for subcontractors foremen and management, and they felt that VM tools are good extra information but not essential. The information given is not that needed since the subcontractors' supervisors tell the crews where to go and what needs to be done. However, the interviews revealed that actually, the crews on site want more information.

At the time of introducing the tools, the supervisors did not have a clear understanding of the tools. The adoption of VM tools during the production phase in construction sites is still low (Tezel et al., 2011), the request for more visual tools and more information from the production perspective points out that a cultural change is necessary and that the information needs to be better located and distributed in the construction sites. The correlation of VM tools with takt production can be seen from interview results and takt progress tracking. When takt progress decreased, the need for VM tools also decreased. It is understandable since the tools' information is not correct, which decreases the overall need for information.

A broader introduction of VM tools on the site would be needed. It is important to think of the most efficient and easy way to educate VM methods. The process of VM implementation should start early. In a takt production project, VM implementation can be started when starting the takt planning phase with subcontractors. This way, the tools are more familiar early on, as the results point out. VM tools were a bit confusing for the subcontractor crews when implemented in the middle of the project. Iteration and testing of these VM tools are also important since the workers might not know what is needed or what they want before they see the right tools, making it challenging to start implementing these tools. The interviews showed that VM tools' need is there, but what information it should include is still unclear, which makes it challenging to develop these tools.

Some interviews pointed out the strong culture in the construction industry that the foremen should give all the work instructions for the crew. In some interviews, VM tools were not thought to have an impact because the crews would only do as their foreman says. In this sense, VM aims, as presented by Galsworth (1997), were not met. However, the result of not having self-regulated crews is common in construction (Reinbold et al., 2020). This brings up a problem in implementing and controlling takt production since some foremen didn't really instruct the crews on what takt production is. In this case, the 
only way to be controlling the work is through the foreman, which means that the foreman needs to be controlling all the time. The study points out that the VM information is there, but it may not be known how to use it or not show the right information for some subcontractors. VM tools and the information it contains should be thought off collaboratively at the beginning of the project to ensure that crews get the information needed.

\section{CONCLUSIONS}

This study aimed to gain knowledge and understanding of VM as part of takt control, as little research exists on how VM tools can support takt control on site in the most efficient way. The study was conducted by implementing and iterating three VM tools on site. The data was collected by triangulation of interviews, work progress observations, and site observations.

VM needs to be introduced early on at the site and collaboratively develop the tools. In takt production, VM tools can help when the information given is clear, recognizable, right and in real-time. VM tools are easy to implement in takt production because takt production plans themselves are visually more understandable than traditional schedules.

Takt boards helped different stakeholders on site to solve problems and coordinate work. They were seen as essential for takt control. Takt cards were seen as being helpful when the information is right and the tool is visible enough, but they still need to be improved to reach full potential for takt control. Takt area markings improve understanding and finding the takt area, which reduces waste in work and makes takt control more efficient.

VM should be implemented in more projects to test which tools and information is needed and most efficient for workers. The lack of real-time information in the project brings up trust issues in VM tools overall. The culture of the information management practices needs to change, and with the help of VM on site, there will be more user experiences and knowledge of VM.

\section{ACKNOWLEDGMENTS}

The research was supported by the Building 2030 consortium of Aalto University and 21 companies.

\section{REFERENCES}

Chauhan, K., Peltokorpi, A., Seppänen, O \& Berghede, K. 2018. "Combining Takt Planning with Prefabrication for Industrialized Construction." Proceedings (IGLC 26). Chennai, India, 848-857.

Dlouhy, J., Binninger M., Oprach, S. \& Haghseno S. 2016. "Three-Level Method of Takt Planning and Takt Control - A New Approach for Designing Production Systems in Construction." Proeedings (IGLC 24). Boston, MA, USA, sect.2, 13-22.

Dlouhy, J. 2018. "Large scale project using takt planning and takt control-creating and sustaining multitasking flow." (IGLC 26).Chennai, India, 1334-1343.

Dresch, A. Lacerda, D. \& Antunes Jr, J. 2015. Design Science Research. A Method for Science and Technology Advancement. Springer International Publishing Switzerland 2015.

Forbes, L. \& Ahmed, S. 2011. Modern Construction Lean Project Delivery and Integrated Practices. Taylor \& Francis Group. 
Formoso, C. T., Santos, A. D. \& Powell, J. 2002. "An Exploratory Study on the Applicability of Process Transparency in Construction Sites". Journal of Construction Research, 3(1), 35-54.

Frandson, A. G. \& Tommelein, I.D., 2014. "Development of a takt-time plan: a case study." In Construction research congress 2014. Reston, VA: American Society of Civil Engineers, 1646-1655.

Galsworth, G.D. 1997. "Visual Systems: Harnessing the Power of Visual Workplace", New York, USA, AMACOM.

Greif, M. 1991. "The Visual Factory: Building Participation through Shared Information", Productivity Press, Portland.

Heinonen, A. \& Seppänen, O. 2016. "Takt Time Planning: Lessons for Construction Industry from a Cruise Ship Cabin Refurbishment Case Study". Proceedings (IGLC 24). Boston, MA. USA, sect. 1. 23-32.

Holmström, J., Ketokivi, M. \& Hameri, A-P. 2009. "Bridging Practice and Theory: A Design Science Approach". Decision Sciences, Volume 40.

Hopp, W. J. \& Spearman, M. L. 2011. Factory physics. Long Grove, IL: Waveland Press.

Koskela, L., Tezel, A., \& Tzortzopoulos, P. 2018. "Why visual management?" Proceedings (IGLC 26). González, V.A. (ed.), Chennai, India, pp. 250-260.

Lehtovaara, J., Seppänen, O., Peltokorpi, A., Kujansuu, P. \& Grönvall, M. 2021. "How takt production contributes to construction production flow: a theoretical model", Construction Management and Economics.

Liker, J. 1997. "Becoming Lean: inside stories of US manufacturers", productivity press, Portland / OR.

Reinbold, A. , Seppänen, O. \& Peltokorpi, A. 2020. “The Role of Digitalized Visual Management to Empower Selfmanaged Crews in Construction Projects". Proceedings (IGLC 28). Berkeley, California, USA. pp 925-936.

Schöttle, A. \& Nesensohn, C. 2019. "The Beauty of a Phase-overlapping Last Planner System with incorporated Takt." Proceedings (IGLC 22). Dublin, Ireland, pp. 441450.

Tezel, A., Koskela, L. \& Tzortzopoulos, P. 2009. "The Functions of Visual Management." International Research Symposium, Salford, UK.

Tezel, A., Koskela, L., Tzortzopoulos, P., Koskenvesa, A. \& Sahlstedt, S. 2011. "An Examination of Visual Management on Finnish Construction Sites" In (IGLC 19). Lima, Peru.

Tezel, A., Koskela, L., Tzortzopoulos, P. \& Alves, T. 2015. Visual Management in Brazilian Construction Companies: Taxonomy and Guidelines for Implementation. Journal of Management in Engineering 31(6).

Vatne, M. \& Drevland, F. 2016. "Practical Benefits of Using Takt Time Planning: A Case Study”. Proceedings (IGLC 24). Boston, MA. USA, sect. 1., 173-182.

Yassine, T., Bacha M., Fayek, F. \& Hamzeh, F. 2014. "Implementing Takt-Time Planning in Construction to Improve Work Flow". Proceedings (IGLC 22). Oslo, Norway.

Yin, R. 2009. Case Study Research. Design and Methods. Fourth Edition. Vol. 5. SAGE Publications Inc. 